\title{
Laparoscopic Appendicectomy in a Patient with Situs Inversus Totalis
}

\author{
Rajan B. Patel • Kamlesh Bhadreshwara • \\ Santosh Hukkeri
}

Received: 17 February 2010 / Accepted: 20 February 2011 /Published online: 2 June 2011

(C) Association of Surgeons of India 2011

\begin{abstract}
Situs inversus totalis (SIT) is a rare condition with a genetic predisposition, wherein organs or organ systems are transposed from their normal sites to locations on the opposite side of the body (the mirror image of normal). The syndrome may include transposition of the thoracic viscera, the abdominal viscera, or more commonly, both. The incidence has been calculated variously as 1 in 6,000-35,000 live births. We present the case of a 22-yearold man with SIT with acute appendicitis. Patient was treated with laparoscopic appendicectomy which is invaluable in both diagnosis and treatment of such patients.
\end{abstract}

Keywords Appendicitis · Situs inversus · Laparoscopic appendicectomy $\cdot$ Acute abdomen

\section{Introduction}

The appendix is a vestigial organ situated on the posteromedial aspect of the caecum and $2.5 \mathrm{~cm}$ below the ileocecal valve. The various positions are retrocecal $(65.3 \%)$, pelvic $(31 \%)$, subcecal $(2.3 \%)$, preileal $(1 \%)$ and postileal $(0.4 \%)$. The rarer types include subhepatic, lateral pouch, mesocoeliac, left-sided (associated with situs

R. B. Patel $\cdot$ K. Bhadreshwara $\cdot$ S. Hukkeri

Department of Surgery, NHL Municipal Medical College,

Ahmadabad, India 380014

R. B. Patel $(\bowtie)$

106, Alkapuri Society, Ghatlodia,

Ahmadabad, India 380061

e-mail: alkarajan2@gmail.com viscerum inversus), intraherniary and lumbar appendicitis (appendix is posterior, lying against the peritoneum behind or below the caecum). Situs inversus totalis (SIT), with an incidence of $0.01 \%$, is an uncommon condition [4]. This publication enforces the advantages and feasibility of laparoscopic appendectomy for appendicitis in such unusual situations.

\section{Case Report}

A 28-year-old man presented with complaints of left iliac fossa pain and vomiting for 2 days. There was no history of fever or urinary symptoms. Physical examination showed tenderness localized to left iliac fossa. Laboratory tests showed a white blood cell count of $10800 / \mathrm{cmm}$ with $86 \%$ neutrophils; other investigations were normal. Chest radiograph showed dextrocardia (Fig. 1). Abdominal ultrasonography showed a left-sided liver, right-sided spleen and $10 \mathrm{~mm}$ inflammed appendix in left iliac fossa. Patient was planned for laparoscopic appendicectomy. Monitor was placed at level of patient's left hip, surgeon stood near patient's right hip and camera assistant at the level of right shoulder. The first port placed was infra-umbilical, $10 \mathrm{~mm}$, with open technique for telescope, which confirmed the ultrasonography findings. Under direct vision, the second $5 \mathrm{~mm}$ port was placed at the suprapubic region, and another $5 \mathrm{~mm}$ port in the left hypochondrium as working ports. Appendix was inflammed, $8-9 \mathrm{~cm}$ in length and retrocaecal in position without any adhesions or free fluid (Fig. 2). Appendicular artery and mesoappendix were cauterized with mono-polar cautery. Appendix was ligated with Roeder's knot, then cut and removed. Patient had an 


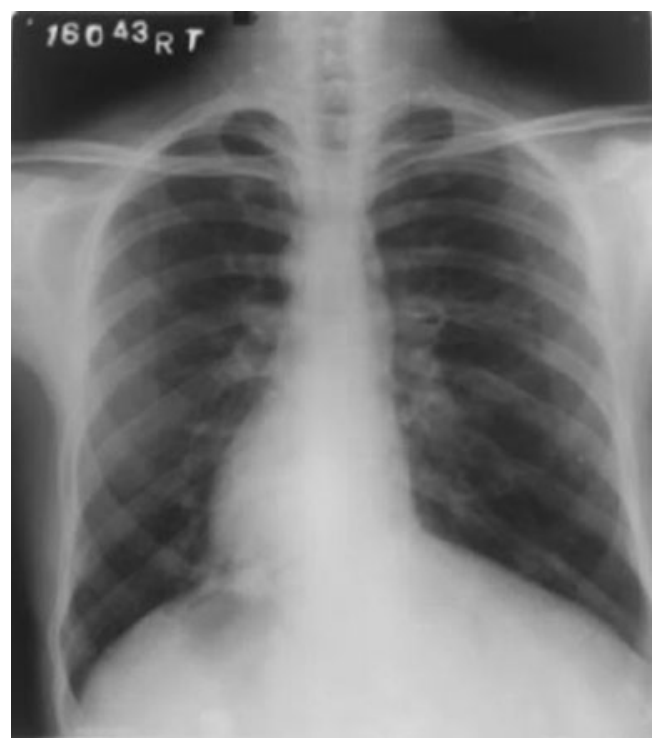

Fig. 1 X-Ray Chest with Dextrocardia

uneventful recovery and all stitches removed on seventh post-operative day.

\section{Discussion}

Situs inversus is considered to have a genetic predisposition, that is autosomal recessive with the defect being localized on the long arm of chromosome 14 [1]. Primarily two different anatomic defects result in a left-sided appendix: situs inversus (SI) and, less commonly, malrotation of the midgut loop. Normal developments require a $270^{\circ}$ counterclockwise rotation, which yields in most cases,

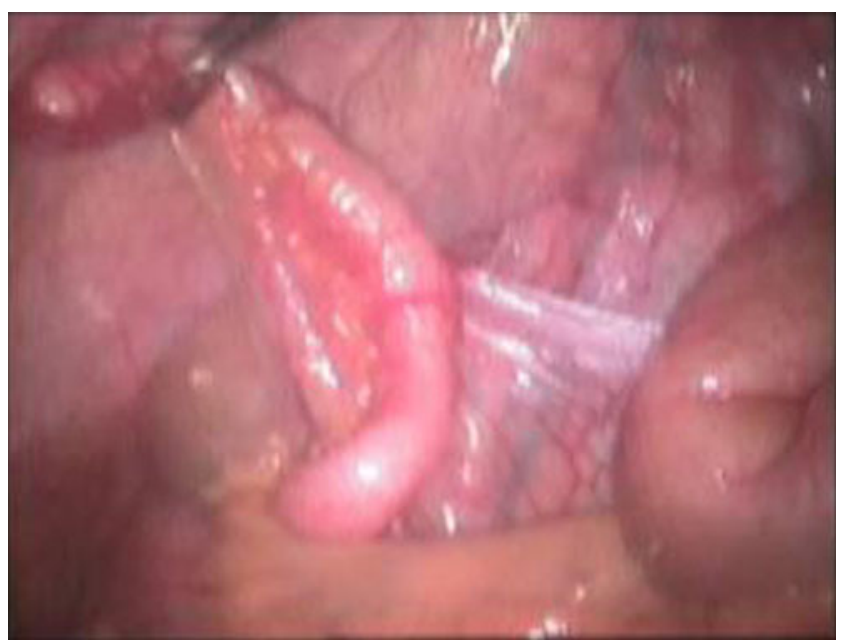

Fig. 2 Acutely inflammed appendix and mesoappendix in LIF a right-sided appendix. SI occurs when the rotation is $270^{\circ}$ clockwise as opposed to a counterclockwise rotation. This then results in the complete reversal of all abdominal, and possibly thoracic, viscera with a left-sided appendix [2].

About $50 \%$ of patients with left-sided appendicitis, for example, have pain on the right side. The appendix is usually located near the caecum in the left lower quadrant in SI. Although the viscera are transposed, the components of the nervous system are not, allowing the patient to experience diffuse abdominal pain. As a result, incisions in inappropriate sites have been documented in more than $40 \%$ of such cases [3].

Laparoscopy is a valuable tool in situations where the diagnosis is in doubt. Not only can the location of the appendix be visualized, but the other organs can be inspected as well. It is far superior to the access provided by a McBurney's incision. Obese patients benefit more from laparoscopy because they need a larger incision than thinner patients, whereas in laparoscopy, the ports are the same for both. The laparoscopic approach has to be tailored for each individual. There are no standard port positions in these situations and the surgeon has to modify the port placements adhering to the basic principles of laparoscopy triangulation and ergonomy [4].

In our patient, we had used the umbilical port as visual port along with left hypochondrium and suprapubic port as working ports. Palanivelu et.al described the umbilical port to be used for the left working hand and a left iliac fossa port for the right working hand. This is a mirror image of the "Two handed" technique that they use for routine laparoscopic appendectomy [4]. Although technically more challenging because of the reverse laparoscopic view of the anatomy, the laparoscopic diagnosis and management of acute appendicitis is indicated in SI [5].

Jonathan Y. Song et. al concluded that patients with a history of SI should undergo an appendectomy at the time of laparoscopy performed for other reasons. Forfeiting this opportunity especially in this type of anatomic defect, will only mean that such patients will be subjected to a potential diagnostic quandary in the future. Removing the appendix eliminates any possibility of future misdiagnoses. It will also exclude the risks of complications that come with delayed diagnosis, such as an appendicular rupture, which can cause infertility in young female patient [3].

The belief was further augmented by Palanivelu et al in his publication "Laparoscopic appendectomy for appendicitis in uncommon situations: the advantage of tailored approach" that the laparoscopic approach for appendectomy is ideal in a patient with SI and should be performed at the time of laparoscopy performed for other reasons. 
Appendectomy should always be done in patients with malrotation and is a part of Ladd's procedure [4].

In conclusion, the laparoscopic approach to an appendectomy is ideal in a patient with SI and should be done prophylactically at the time of laparoscopy performed for any reason.

Acknowledgements Dr. Pankaj Patel, Dean, NHL Municipal Medical College.

Dr. V.M. Valu, Prof. of Surgery, NHL Municipal Medical College

Sources of Support NIL

Presenting at a Meeting NIL

Conflicting Interest NIL

\section{References}

1. Morris E, Franklin J Jr, Almeida A, Pérez ER, Robert LP, Michaelson AM (2001) Cholecystectomy and appendectomy by laparoscopy in a patient with situs inversus totalis. Assoc Mex Cir Endoscópica 2(3):150-153

2. Golash V (2006) Laparoscopic management of acute appendicitis in situs inversus. J Minimal Access Surg 2(4):220-222

3. Song JY, Rana N, Rotman CA (2004) Laparoscopic appendectomy in a female patient with situs inversus. JSLS 8:175-177

4. Palanivelu C, Rangarajan M, John SJ, Senthilkumar R, Madhankumar MV (2007) Laparoscopic appendectomy for appendicitis in uncommon situations: the advantages of a tailored approach. Singapore Med J 48 (8):737-740

5. Ucar AE, Ergul E, Aydin R, Ozgun YM, Korukluoglu B (2007) Left-sided acute appendicitis with situs inversus totalis. Internet $\mathrm{J}$ Surg 12(2):9 